\title{
BHLH Protein
}

National Cancer Institute

\section{Source}

National Cancer Institute. BHLH Protein. NCI Thesaurus. Code C17906.

bHLH class proteins are sequence-specific DNA-binding proteins that contain a conserved 50-amino acid HLH domain consisting of two alpha-helices separated by a variable loop sequence, adjacent to a sequence that is highly enriched in basic amino acids. The HLH region mediates protein dimerization, while the basic region mediates sequence-specific DNA binding. Many bHLH proteins recognize a DNA sequence known as the E box. Class A bHLH proteins are ubiquitously expressed, while class B bHLH proteins are expressed in specific cell types. In general, class B proteins preferentially bind to DNA as heterodimers with class A proteins and function as transcriptional activators. 